\title{
The difference in serum alkaline phosphatase levels between girls with precocious puberty and those with normal puberty
}

\author{
Hye Jeong Jwa, MD, \\ Soo In Yang, MD, \\ Han Hyuk Lim, MD \\ Department of Pediatrics, \\ Chungnam National University \\ School of Medicine, Daejeon, Korea
}

Purpose: Serum alkaline phosphatase (ALP) level is the most valid marker of bone formation. Precocious puberty (PP) in girls is characterized by early growth acceleration. The aim of this study was to determine whether serum ALP levels differ between girls with PP and those with normal puberty, and whether ALP level varies with age or Tanner stage.

Methods: This retrospective study included girls with PP ( $n=61)$ and normal puberty $(n=71)$ who visited the outpatient clinic at Department of Pediatrics, Chungnam National University Hospital from March 2010 to August 2011. We obtained age, height, parental height, weight, bone age, Tanner stage, and concentrations of luteinizing hormone, follicular-stimulating hormone, estradiol, ALP, and insulin-like growth factor-1 (IGF-1) from the participants' medical records.

Results: Age and predicted adult height were significantly lower in girls with PP than in those with normal puberty. The height standard deviation score (SDS), weight SDS, body mass index, midparental height, bone age, and IGF-1 level were higher in girls with PP than in those with normal puberty. ALP level was significantly higher in 5- to 8-year-old girls with PP than in age-matched girls with normal puberty. The mean ALP levels were higher in girls with PP than bone age-matched girls with normal puberty $(P=0.0003)$

Conclusion: Serum ALP level showed the significance differences between girls with PP and those with normal puberty. The reasons for and the mechanisms underlying this elevation in serum ALP level in girls with PP should be investigated further.

Keywords: Precocious puberty, Serum alkaline phosphatase, Bone
Received: 2 October, 2013 Revised: 23 October, 2013 Accepted: 11 November, 2013

Address for correspondence: Han Hyuk Lim, MD

Department of Pediatrics, Chungnam National University Hospital, Chungnam National University School of Medicine, 282 Munhwa-ro, Jung-gu, Daejeon 301-721, Korea

Tel: +82-42-280-7825

Fax: +82-42-255-3158

E-mail:damus@cnuh.or.kr

\section{Introduction}

One of the hallmarks of puberty is growth in stature. A key element of puberty is a second growth spurt that is characterized by markedly increased bone turnover and rate of bone growth. A previous study showed that bone turnover and bone growth are maximal in midpuberty (Tanner stage 3 ) and decrease toward the adult level in late puberty (Tanner stage $4-5)^{11}$. A substantial pubertal growth spurt can occur in girls with precocious puberty (PP), which is defined as early breast development emerging before 8 years of age ${ }^{2)}$. PP is associated with extreme sensitivity of the growth plate to the actions of estrogens; the auxological consequences of PP often precede the signs of sexual maturation, and PP can cause premature fusion of the growth plates ${ }^{3}$.

Serum alkaline phosphatase (ALP) level is recognized as an indicator of osteoblastic activity and is used widely in routine biochemical tests because it can be measured in almost all laboratories ${ }^{4,5}$.

The aim of the present study was to investigate the interrelationships between pubertal 
development and biochemical markers of bone formation (serum ALP level) to evaluate whether bone-formation activity differs between girls with PP and those with normal puberty and whether the differences are associated with age and Tanner stage.

\section{Materials and methods}

\section{Subjects}

The study protocol was performed after informed consent was obtained from the patients and their legitimate guardians. One hundred thirty-two girls (61 PP patients and 71 non-PP controls) were selected from among the children who visited the outpatient - short stature and PP clinic in the Department of Pediatrics, Chungnam National University Hospital, between March 2010 and August 2011.

The subjects were classified into PP and non-PP groups. PP was defined as either early menarche before the age of 10 years or Tanner stage breast 2 or greater for breast development before 8 years of age accompanied by bone age (BA) advanced by at least 1 year compared with chronological age (CA) and a serum luteinizing hormone (LH) level $>5.0$ IU/L in the course of a gonadotropin-releasing hormone $(\mathrm{GnRH})$ stimulation test. Girls aged $\geq 9$ years who had no breast development before 9 years of age and no advanced BA $(\leq 1$ year less than CA), or girls $<9$ year-old with Tanner stage breast 1 and no advanced BA, or who had achieved menarche at an age $\geq 13$ years were included as non-PP controls. Girls who had an underlying disorder or history of medication such as steroids, growth hormone, or GnRH analogues, or who were overweight or obese (body mass index $[\mathrm{BMI}] \geq 85$ th percentile) were excluded.

\section{Methods}

The subjects' medical records were reviewed retrospectively, and information on age, height, body weight, pubertal stage (using Tanner stage for breasts), parental height, the presence of illness, and past illness were recorded. Height was measured using a Harpenden stadiometer accurate to the nearest $0.1 \mathrm{~cm}$ during a visit to the clinic. Body weight was recorded to the nearest $0.1 \mathrm{~kg}$ with an electric scale. Pubertal stage according to Marshall and Tanner was determined by one pediatric endocrinologist at each visit. Midparental height (MPH) was the mean of the parental heights minus $6.5 \mathrm{~cm}$. BMI was calculated as weight $(\mathrm{kg}) /$ height $(\mathrm{m})^{2}$. The standard deviation scores (SDSs) of height, weight, and BMI were calculated using the 2007 growth reference tables for Korean children and adolescents of the Korean Pediatric Society and Korea Centers for Disease Control and Prevention ${ }^{6}$. BA was determined using Greulich and Pyle's atlas ${ }^{7}$.

Blood samples were drawn for measurement of the levels of estradiol (E2), basal LH and follicle-stimulating hormone (FSH), peak LH and FSH after a GnRH stimulation test, insulin-like growth factor-1 (IGF-1), liver function test, electrolytes (calcium, phosphorus), and thyroid function test. Serum LH and FSH levels were measured at baseline and 15,30,45, 60, and 90 minutes after intravenous bolus administration of GnRH (100 $\mu$ g Relefact, Sanofi-Aventis, Frankfurt am Main, Germany). A stimulated LH value $>5 \mathrm{IU} /$ $\mathrm{L}$ is considered to indicate a pubertal response to the GnRHstimulation test ${ }^{8-10)}$. The serum levels of LH, FSH, and E2 were measured by electrochemiluminescence immunoassays, and IGF- 1 by a chemiluminescence immunoassays. Serum ALP level was measured using using Bayer Reagent Packs on an automated chemistry analyzer (Advia 1650 Autoanalyzer, Bayer Diagnostics, Leverkusen, Germany). We considered the manufacturers' details for all assays.

\section{Statistics}

The numeric data are expressed mean \pm standard deviation or median (range). We analyzed the differences in auxological and clinical data between groups using Student $t$-test. Differences in serum ALP levels between the PP and non-PP groups were analyzed according to age and Tanner stage using the MannWhitney $U$ test. The mean serum ALP levels between the PP and BA-matched non-PP groups were analyzed using two way analysis of variance with Graphpad prism (GraphPad Software Inc., San Diego, CA, USA). Data analyses were performed using IBM SPSS ver. 20.0 (IBM Co., Armonk, NY, USA), and a $P$-value $<0.05$ was considered significant.

\section{Results}

\section{Auxological and laboratory manifestations}

The baseline clinical and laboratory characteristics of the study participants are shown in Table 1. A total of 132 girls (61 girls with PP and 71 with normal puberty) were enrolled in the trial. The age $(P<0.001)$ and predicted adult height $(P$ $<0.001)$ were significantly lower in the PP group than in the non-PP group. The height SDS $(P<0.001)$, weight SDS $(P$ $<0.001)$, BMI $(P=0.046), \mathrm{MPH}(P=0.009)$, BA $(P=0.006)$, and IGF-1 level $(P=0.005)$ were higher in the PP group than in the non-PP group. However, height, weight, BMI-SDS, and basal LH, FSH, estradiol, and aspartate aminotransferase, alanine aminotransferase, calcium, and phosphorous levels did not differ significantly between the PP and non-PP groups.

\section{Difference in serum ALP levels between the PP and non-PP groups according to age}

The age-related changes in serum ALP levels in the PP and non-PP groups are shown in Table 2 and Fig. 1. Two 8-yearold and five 9-year-old girls in the PP group were diagnosed with early menarche and Tanner stage 4 . Serum ALP level was significantly higher in 5- to 8-year-old girls in the PP group than 
in girls of the same age in the non-PP group $(P<0.05)$. At age 9 years, the difference between the two groups was not significant $(P=0.065)$.

\section{Difference in serum ALP levels between the PP and non-PP groups according to BA}

The BA-related differences in serum ALP levels in the PP and non-PP groups are shown in Fig. 2. The mean serum ALP level was significantly higher in girls with $\mathrm{PP}$ group than in girls of the same bone aged non-PP group $(P=0.0003)$.

Table 1. Clinical and laboratory findings in patients with precocious puberty and controls

\begin{tabular}{lrcr}
\hline Variable & $P P(n=61)$ & Non-PP $(n=71)$ & $P$-value \\
\hline Age (yr) & $7.8 \pm 1.3$ & $9.8 \pm 2.5$ & $<0.001$ \\
Height (cm) & $132.1 \pm 7.7$ & $129.7 \pm 13.1$ & 0.209 \\
Height SDS & $1.2 \pm 0.8$ & $-0.6 \pm 1.0$ & $<0.001$ \\
Weight (kg) & $31.5 \pm 6.6$ & $29.3 \pm 10.0$ & 0.143 \\
Weight SDS & $1.0 \pm 0.8$ & $-0.5 \pm 1.3$ & $<0.001$ \\
BMI (kg/m²) & $17.9 \pm 2.4$ & $16.9 \pm 3.0$ & 0.046 \\
BMI-SDS & $0.5 \pm 0.9$ & $-1.5 \pm 9.5$ & 0.106 \\
MPH (cm) & $159.4 \pm 3.6$ & $157.7 \pm 3.4$ & 0.009 \\
PAH (cm) & $151.2 \pm 5.3$ & $156.5 \pm 5.5$ & $<0.001$ \\
Bone age (yr) & $10.3 \pm 1.4$ & $9.3 \pm 2.6$ & 0.006 \\
Basal LH (IU/L) & $1.1 \pm 2.1$ & $1.4 \pm 1.8$ & 0.446 \\
Basal FSH (IU/L) & $3.7 \pm 3.8$ & $3.7 \pm 1.1$ & 0.943 \\
Estradiol (pg./mL) & $12.7 \pm 8.3$ & $13.8 \pm 15.4$ & 0.692 \\
IGF-1 (ng/mL) & $306.5 \pm 102.8$ & $242.8 \pm 131.6$ & 0.005 \\
AST (IU/L) & $23.1 \pm 4.3$ & $23.9 \pm 4.6$ & 0.364 \\
ALT (IU/L) & $13.4 \pm 5.5$ & $13.0 \pm 3.9$ & 0.699 \\
Calcium (mg/dL) & $9.6 \pm 0.4$ & $9.6 \pm 0.3$ & 0.268 \\
Phosphorous (mg/dL) & $5.1 \pm 0.4$ & $5.0 \pm 0.4$ & 0.255
\end{tabular}

Values are presented as mean \pm standard deviation. $P$-values were calculated by Student $t$-test.

PP, precocious puberty; SDS, standard deviation score; BMI, body mass index; MPH, midparental height; $\mathrm{PAH}$, predicted adult height; $\mathrm{LH}$ luteinizing hormone; FSH, follicular stimulating hormone; IGF-1, insulinlike growth factor-1; AST, aspartate aminotransferase; ALT, alanine aminotransferase.

Table 2. Comparison of serum alkaline phosphatase levels according to age

\begin{tabular}{|c|c|c|c|c|c|}
\hline \multirow{2}{*}{ Age (yr) } & \multicolumn{2}{|r|}{$P P(n=61)$} & \multicolumn{2}{|c|}{ Non-PP $(n=71)$} & \multirow{2}{*}{$P$-value $e^{a)}$} \\
\hline & No. & $\mathrm{ALP}(\mathrm{IU} / \mathrm{L})$ & No. & $\mathrm{ALP}(\mathrm{IU} / \mathrm{L})$ & \\
\hline $5.0-5.9$ & 5 & $313(299-338)$ & 5 & $266(210-271)$ & 0.009 \\
\hline $6.0-6.9$ & 8 & $308(262-400)$ & 9 & $261(212-292)$ & 0.003 \\
\hline $7.0-7.9$ & 16 & $340(246-607)$ & 7 & $265(208-388)$ & 0.023 \\
\hline $8.0-8.9$ & 24 & $345(223-575)$ & 8 & $280(212-338)$ & 0.001 \\
\hline $9.0-9.9$ & 8 & $322(273-530)$ & 15 & $288(210-515)$ & 0.065 \\
\hline $10.0-10.9$ & - & - & 11 & $301(158-406)$ & \\
\hline$\geq 11.0$ & - & - & 16 & $253(75-388)$ & \\
\hline
\end{tabular}

Values are presented as median (range).

PP, precocious puberty; ALP, alkaline phosphatase.

${ }^{\text {a) }}$ Statistical significance test was done by Mann-Whitney $U$ test.

\section{Discussion}

Serum ALP levels were higher in the girls with PP than in the controls. The peak ALP level was observed in Tanner stage 3 in the controls but in Tanner stage 4 in PP patients. We have tried to clarify how changes in serum ALP level according to age and Tanner stage in girls with PP was compared to those with normal puberty, whether serum ALP level was the biomarker to help the additional diagnostic information at initial visit in outpatient clinic.

PP is one of the most common endocrine disorders seen by primary care clinicians and continues to be a major cause of concern for both parents and health care providers. The diagnosis of PP is based on the medical history, physical examination, pubertal staging, and BA. The GnRH-stimulation test is the gold standard for proving premature activation of the hypothalamic-pituitary-gonadal axis ${ }^{11,12)}$. Rapid growth

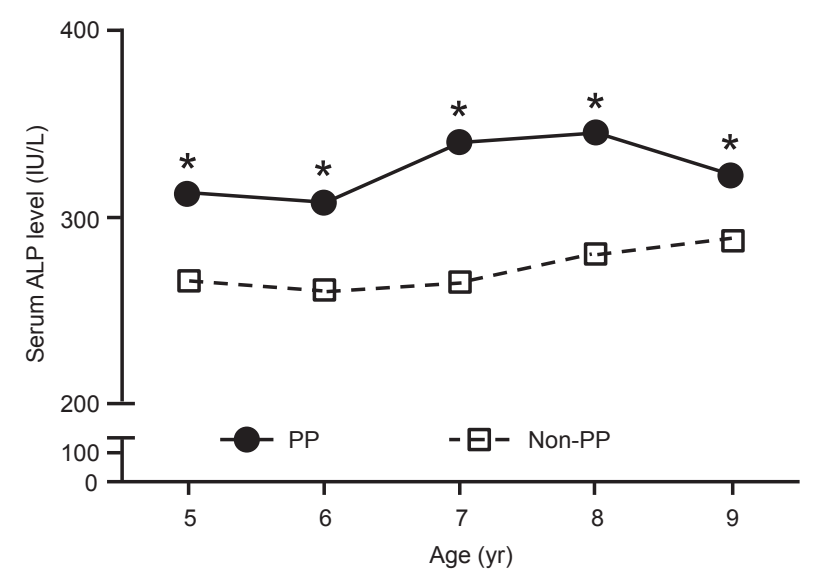

Fig. 1. Serum alkaline phosphatase (ALP) level according to age. The serum ALP levels were higher in girls with precocious puberty (PP) than in girls of the same age with normal puberty (non-PP). The data are expressed as mean values. *Indicates significant differences $(P<0.05)$.

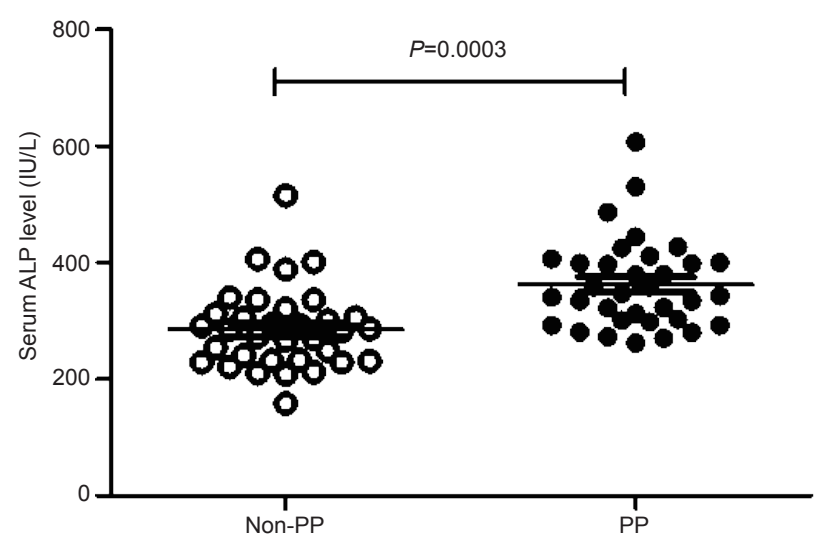

Fig. 2. Serum alkaline phosphatase (ALP) level adjusted by bone age. The total serum ALP levels were higher in girls with precocious puberty (PP) than in girls with bone age-matched normal puberty (non-PP) $(P=0.0003)$. 
velocity is suggested as the most useful predictor of a positive result on the GnRH-stimulation test, indicating that the clinician can decide the proper timing of the GnRH-stimulation test by estimating the growth velocity ${ }^{13)}$. However, the following visit may be needed to evaluate patient's growth velocity.

PP is manifested by early bone maturation ${ }^{14-16)}$. Biochemical markers of bone metabolism exhibit dynamic changes during both bone growth and remodeling, and their measurement may be useful in the assessment of metabolic bone diseases and growth disorders in children ${ }^{14,17)}$. Bone markers are classified according to the processes they reflect, namely formation and resorption. The levels of bone formation markers increase during different phases of osteoblast development and reflect osteoblast function and bone formation. These markers include ALP, bone-specific ALP, osteocalcin, and procollagen 1 peptides.

Total serum ALP activity is used as a biochemical marker of bone formation to confirm osteoblastic activity in primary hyperparathyroidism, rickets, osteomalacia, and Paget disease. Because ALP is a marker of osteoblastic activity, its level is higher in growing children than in fully grown adults, and the highest ALP level is detected during the rapid growth phases of childhood such as infancy and puberty ${ }^{18}$. A few study for bone markers in children and adolescents have been demonstrated that serum ALP and bone-specific ALP showed same course with age and Tanner stage, and higher bone specific ALP values at the beginning of puberty Tanner stage 2 , aged $10-12$ years ${ }^{18,}$ 19)

The ALP levels in the non-PP controls in this study correspond well with those of an earlier study showing that, in girls, serum ALP levels are at a maximum in midpuberty Tanner stage $2-3$ but decrease in late puberty Tanner stage $3-4^{20)}$. We also found that the girls with PP had higher levels of serum ALP than controls after adjustment for age. The ALP levels in the 9-year-old subgroup did not differ significantly between the PP and non-PP groups, probably because of the small sample size (Table 2). Our findings suggest that, among girls with suspected early breast budding, those with a high serum ALP level are more likely to be in PP compared to same-aged girls.

Interestingly, the mean serum ALP levels significantly differed between the patients and controls by BA-matched study. This cause is not known, but the degree of bone formation between PP and non-PP girls may be some different according to age or BA.

Our study has some limitations. This was a cross-sectional, retrospective study with a small sample size. We did not measure individual longitudinal changes in ALP levels in the girls with PP. The serum ALP level did not adjusted by serum vitamin D level. And we used the total ALP instead of bone-specific ALP.

In conclusion, among girls with suspected early breast budding, those with a high serum ALP level are more likely to be in PP compared to same-aged and same-bone aged girls. Further study is needed to understand the reasons for the difference in serum ALP levels between girls with PP and those with normal puberty according to BA.

\section{Conflict of interest}

No potential conflict of interest relevant to this article was reported.

\section{References}

1. Mora S, Pitukcheewanont P, Kaufman FR, Nelson JC, Gilsanz V. Biochemical markers of bone turnover and the volume and the density of bone in children at different stages of sexual development. J Bone Miner Res 1999;14:1664-71.

2. Dattani MT, Hindmarsh PC. Normal and abnormal puberty. In: Brook CG, Clyton PE, Brown RS, Savage MO, editors. Brook's clinical pediatric endocrinology. 5th ed. Oxford: Blackwell Publishing, 2005:183-201.

3. Carel JC, Lahlou N, Roger M, Chaussain JL. Precocious puberty and statural growth. Hum Reprod Update 2004; 10:135-47.

4. Warnes TW. Alkaline phosphatase. Gut 1972;13:926-37.

5. Fleisher GA, Eickelberg ES, Elveback LR. Alkaline phosphatase activity in the plasma of children and adolescents. Clin Chem 1977;23:469-72.

6. Korea Centers for Disease Control and Prevention, Division of Chronic Disease Surveillance, Committee for the Development of Growth Standard for Korean Children and Adolescents; Korean Pediatric Society, Committee for School Health and Public Health Statistics. 2007 Korean children and adolescents growth standard (commentary for the development of 2007 growth chart). Cheongwon: Korea Centers for Disease Control and Prevention, Division of Chronic Disease Surveillance, 2007.

7. Greulich WW, Pyle SI. Radiographic atlas of skeletal development of the hand and wrist. 2nd ed. Stranford (CA): Stranford University Press, 1959.

8. Neely EK, Hintz RL, Wilson DM, Lee PA, Gautier T, Argente J, et al. Normal ranges for immunochemiluminometric gonadotropin assays. J Pediatr 1995;127:40-6.

9. Iughetti L, Predieri B, Ferrari M, Gallo C, Livio L, Milioli S, et al. Diagnosis of central precocious puberty: endocrine assessment. J Pediatr Endocrinol Metab 2000;13 Suppl 1:709-15.

10. Brito VN, Batista MC, Borges MF, Latronico AC, Kohek $\mathrm{MB}$, Thirone AC, et al. Diagnostic value of fluorometric assays in the evaluation of precocious puberty. J Clin Endocrinol Metab 1999;84:3539-44.

11. Poomthavorn P, Khlairit P, Mahachoklertwattana P. Subcutaneous gonadotropin-releasing hormone agonist (triptorelin) test for diagnosing precocious puberty. Horm Res 2009;72:114-9.

12. Lee PA. Laboratory monitoring of children with precocious puberty. Arch Pediatr Adolesc Med 1994;148:369-76.

13. Nam HK, Rhie YJ, Son CS, Park SH, Lee KH. Factors to predict positive results of gonadotropin releasing hormone 
stimulation test in girls with suspected precocious puberty. J Korean Med Sci 2012;27:194-9.

14. Jurimae J. Interpretation and application of bone turnover markers in children and adolescents. Curr Opin Pediatr 2010;22:494-500.

15. Orwoll ES, Miller PD, Adachi JD, Brown J, Adler RA, Kendler D, et al. Efficacy and safety of a once-yearly i.v. Infusion of zoledronic acid $5 \mathrm{mg}$ versus a once-weekly 70 $\mathrm{mg}$ oral alendronate in the treatment of male osteoporosis: a randomized, multicenter, double-blind, active-controlled study. J Bone Miner Res 2010;25:2239-50.

16. Weldon D. The effects of corticosteroids on bone growth and bone density. Ann Allergy Asthma Immunol 2009;103:3-11.
17. Delmas PD. Biochemical markers of bone turnover. J Bone Miner Res 1993;8 Suppl 2:S549-55.

18. Turan S, Topcu B, Gokce I, Guran T, Atay Z, Omar A, et al. Serum alkaline phosphatase levels in healthy children and evaluation of alkaline phosphatase $z$-scores in different types of rickets. J Clin Res Pediatr Endocrinol 2011;3:7-11.

19. Huang Y, Eapen E, Steele S, Grey V. Establishment of reference intervals for bone markers in children and adolescents. Clin Biochem 2011;44:771-8.

20. Abrams SA, Copeland KC, Gunn SK, Gundberg CM, Klein $\mathrm{KO}$, Ellis KJ. Calcium absorption, bone mass accumulation, and kinetics increase during early pubertal development in girls. J Clin Endocrinol Metab 2000;85:1805-9. 